\title{
Relation of dietary and lifestyle traits to difference in serum leptin of Japanese in Japan and Hawaii: The INTERLIPID Study
}

\author{
Yasuyuki Nakamura ${ }^{1,2}$, Hirotsugu Ueshima², Nagako Okuda ${ }^{2}$, Katsuyuki Miura $^{2}$, Yoshikuni \\ Kita $^{2}$, Tomonori Okamura ${ }^{3}$, Tanvir C Turin ${ }^{2}$, Akira Okayama ${ }^{4}$, Beatriz Rodriguez ${ }^{5}$, J David \\ Curb $^{5}$, and Jeremiah Stamler ${ }^{6}$ for the INTERLIPID Research Group \\ ${ }^{1}$ Cardiovascular Epidemiology, Kyoto Women's University, Japan \\ ${ }^{2}$ Department of Health Science, Shiga University of Medical Science, Japan \\ ${ }^{3}$ Department of Preventive Cardiology, National Cardiovascular Center, Japan \\ 4 Japan Anti-Tuberculosis Association, Tokyo, Japan \\ ${ }^{5}$ Department of Geriatric Medicine, John A Burns School of Medicine, University of Hawaii, \\ Honolulu, HI, USA \\ ${ }^{6}$ Feinberg School of Medicine, Northwestern University, Chicago, IL, USA.
}

\begin{abstract}
Background and Aims-Previously, we found significantly higher serum leptin in JapaneseAmericans in Hawaii than Japanese in Japan. We investigated whether differences in dietary and other lifestyle factors explain higher serum leptin concentrations in Japanese living a Western lifestyle in Hawaii compared with Japanese in Japan.
\end{abstract}

\begin{abstract}
Methods and Results-Serum leptin and nutrient intakes were examined by standardized methods in men and women ages 40 to 59 years from two population samples, one JapaneseAmerican in Hawaii (88 men, 94 women), the other Japanese in central Japan (123 men, 111 women). Multiple linear regression models were used to assess role of dietary and other lifestyle traits in accounting for serum leptin difference between Hawaii and Japan. Mean leptin was significantly higher in Hawaii than Japan $(7.2 \pm 6.8$ vs $3.7 \pm 2.3 \mathrm{ng} / \mathrm{ml}$ in men, $\mathrm{P}<0.0001 ; 12.8 \pm 6.6$ vs $8.5 \pm 5.0$ in women $<0.0001)$. In men, higher BMI in Hawaii explained over $90 \%$ of the difference in serum leptin; in women, only $47 \%$. In multiple linear regression analyses in women, further adjustment for physical activity and dietary factors - - alcohol, dietary fiber, iron- produced a further reduction in the coefficient for the difference, total reduction $70.7 \%$; $\mathrm{P}$ value for the Hawaii-Japan difference became 0.126 .
\end{abstract}

Conclusion-The significantly higher mean leptin concentration in Hawaii than Japan may be attributable largely to differences in BMI. Differences in nutrient intake in the two samples were associated with only modest relationship to the leptin difference.

(c) 2010 Elsevier B.V. All rights reserved.

Address correspondence and reprint requests to: Yasuyuki Nakamura, MD, Cardiovascular Epidemiology, Kyoto Women's University 35 Imakumano Kitahiyoshi-cho, Higashiyama-ku, Kyoto 605-8501, JAPAN FAX: +81-75-531-2162, Phone: +81-75-531-2162 nakamury@kyoto-wu.ac.jp.

Publisher's Disclaimer: This is a PDF file of an unedited manuscript that has been accepted for publication. As a service to our customers we are providing this early version of the manuscript. The manuscript will undergo copyediting, typesetting, and review of the resulting proof before it is published in its final citable form. Please note that during the production process errors may be discovered which could affect the content, and all legal disclaimers that apply to the journal pertain. 


\section{Introduction}

Leptin, named after the Greek leptos meaning thin, was identified by positional cloning of the mouse obese $(o b)$ gene as a key molecule in the physiological regulation of body weight and energy balance [1]. Leptin is produced and secreted mainly by adipocytes. It acts on the hypothalamus, altering energy intake by decreasing appetite and increasing energy expenditure via sympathetic stimulation of several tissues [2]. Obese individuals, however, remain hyperphagic despite their high circulating leptin concentrations, indicating hypothalamic insensitivity to leptin [3]. Despite hypothalamic leptin resistance, the sympathoexcitatory effect of leptin is preserved after either systemic or central neural administration of leptin [4]. These findings led to the concept of selective leptin resistance [5].

INTERLIPID, an ancillary study of the International Study of Macro/micronutrients and Blood Pressure (INTERMAP), investigated coronary heart disease (CHD) risk factors in four Japanese population samples in Japan and a Japanese-American population sample in Hawaii [6,7]. In INTERMAP, dietary surveys were conducted with a highly standardized protocol in 17 random population samples in four countries (Japan, People's Republic of China, the U.K., and the U.S.) [8].

Although there have been several studies on the association between dietary intakes and leptin concentrations, discrepancies are found as to the effects of alcohol and macronutrients on leptin. [16-21]. Since our samples included Japanese in Japan and Japanese-Americans; an ethnically homogenous cohort with a wide range of BMIs (from 17.2 to $47.0 \mathrm{~kg} / \mathrm{m}^{2}$ ) due to differences in lifestyle related factors, we thought we might be able to solve the problems on the relationship between dietary factors and serum leptin concentration. Furthermore, in INTERLIPID data analyses, we found for both genders significantly higher serum leptin concentrations of middle-aged Hawaiian Japanese-Americans than Japanese living in Japan. We hypothesized that these differences are largely related to differences in dietary and nondietary lifestyle factors between the two population samples; data from previous studies show that Japanese-Americans in Hawaii and Japanese in Japan have significantly different dietary patterns as well as body mass index (BMI) [6-8].

\section{Methods}

Detailed methods of the INTERMAP Study have been described [8]. They are summarized here. Two standardized blood pressure measurements were made on each participant on four different days; medical and lifestyle data were collected with standardized forms; four indepth multi-pass 24-h dietary recalls and two timed 24-h urine collections were obtained. In addition, non-fasting blood was drawn from INTERLIPID participants [6,7]. We used data on analytes measured in these samples, as well as INTERMAP dietary and other data.

\section{Participants}

INTERLIPID participants ages 40-59 years were from five INTERMAP research centers: four in Japan and one in Hawaii [6,7]. For the present study, serum leptin concentrations were measured in two samples, one from Japan and one from Hawaii. The two populations samples were: (1) Japanese residents in Aito Town, a rural town in Shiga prefecture, central Japan (129 men and 129 women) and (2) third and fourth generation offspring of Japanese emigrants living in Honolulu, Hawaii (100 men and 106 women). Participants in Honolulu were asked about the ethnicity of their mother and father; those included in the study responded 100\% Japanese to both. Aito Town was chosen because it was the only Japanese community sample; the other three samples were of factory workers. There were only small differences in lifestyle and dietary habits among the four samples in Japan; differences of 
those variables between Japan and Hawaii samples were larger [8] Among those in these two samples, 48 persons (24 Japanese, 24 Japanese-American) were excluded because volume of their stored serum specimen was not enough to measure leptin, leaving 234 Japanese individuals (123 men and 111 women) and 182 Japanese-Americans ( 88 men and 94 women).

Ethics committees of the Shiga University of Medical Science, the Pacific Health Research Institute, and Northwestern University approved the study protocol. Written informed consent was obtained from all participants.

\section{Anthropometric and lifestyle assessment}

Participants visited the research centers four times on two pairs of consecutive days three weeks apart on average. Height and weight with light clothes were measured at each visit. Using a questionnaire, trained certified observers inquired about physical activity, smoking status, previous medical history of cerebro-cardiovascular diseases/diabetes, use of medication, et al. Hypertension was defined as systolic blood pressure $\geq 140 \mathrm{mmHg}$, diastolic blood pressure $\geq 90 \mathrm{mmHg}$, or use of anti-hypertensive medication. Diabetes mellitus was defined as $\mathrm{HbA} 1 \mathrm{c} \geq 6.5 \%$, or use of anti-diabetic medication.

\section{Dietary assessment}

Four in-depth multi-pass 24-h dietary recalls per participant were conducted during the four visits by specially trained dietary interviewers. Prior to data collection, a supervising nutritionist in each country trained all interviewers and certified that they had the appropriate skills to conduct dietary interviews and process dietary data using computers. Standardized on-going quality control procedures were adopted to optimize quality of dietary data throughout data collection [8]. All participants for the present study attended all 4 study visits; their energy intakes from all 24-hour dietary recalls were between 500 and $5000 \mathrm{kcal} / \mathrm{day}$.

\section{Biochemical measurements}

For the INTERLIPID Study, non-fasting blood was drawn on the second day of the first two-day visit pair. Serum and plasma were obtained by centrifugation within $30 \mathrm{~min}$ of blood drawing and immediately refrigerated. Within 24-hours, all specimens were frozen and stored locally at $-70^{\circ} \mathrm{C}$. Samples from the Hawaiian and Japanese centers were shipped to a central laboratory in Japan on dry ice. Individual samples from the two centers were randomly allocated for analysis to avoid systematic measurement bias. The central laboratory was standardized by the Lipid Standardization Program, Centers for Disease Control and Prevention, Atlanta, GA, U.S.A.; it successfully met the criteria of precision and accuracy of control [9]. The laboratory is currently a member of the Cholesterol Reference Method Laboratory Network (CRMLN) [10]. Serum concentrations of total cholesterol (TCH), high-density lipoprotein cholesterol (HDL-C), and low-density lipoprotein cholesterol (LDL-C) were directly measured by enzymatic methods on an auto-analyzer (Hitachi 7107, Tokyo, Japan). Serum leptin concentrations were measured by immunoassays from Linco Research [Millipore (Billerica, MA)]. We included standard sera of known values with each batch; there were no significant differences in the standard serum concentrations among the batches. The analytical coefficients of variation $(\mathrm{CV})$ were less than $3 \%$ for TCH, LDL-C, HDL-C, and triglycerides. Although significant postprandial increase in blood triglyceride concentrations occurs, postprandial stability of TCH, HDL-C, and LDL-C have been demonstrated [11]. Postprandial stability of leptin also has been shown in normal and obese persons, as well as in patients with type II diabetes mellitus [12] 


\section{Data analyses}

For each person, means of the individual nutrients from the four 24-h dietary recalls were used in the analyses. Data are presented as the contribution to total energy intake ( $\% \mathrm{kcal})$ from total available carbohydrates, total fat, monounsaturated fatty acids (MUFA), saturated (SFA), polyunsaturated (PUFA), long chain n-3 PUFAs, alinolenic acid, n-6 PUFA, linoleic acid, dietary cholesterol $(\mathrm{mg} / 1000 \mathrm{kcal})$, total dietary fiber $(\mathrm{g} / 1000 \mathrm{kcal})$, magnesium $(\mathrm{mg} /$ $1000 \mathrm{kcal})$, iron $(\mathrm{mg} / 1000 \mathrm{kcal})$, phosphorus $(\mathrm{mg} / 1000 \mathrm{kcal})$, and alcohol $(\% \mathrm{kcal})$. In INTERMAP, intakes of arachidonic acid (ARA, n20:4), eicosapentaenoic acid (EPA, n20:5), docosahexaenoic (DHA, n22:6), and docosapentaenoic acid (DPA, n22:5) were estimated. ARA intake was included in the analyses because of its reported adverse (including atherogenic) effects. Intakes of EPA, DHA, and DPA were included since fish intake was sizably higher among Japanese in Japan than among Japanese-Americans in Hawaii. EPA, DHA, and DPA intakes of individuals were highly intercorrelated (Pearson partial correlation coefficients between any two of the three fatty acids greater than 0.9). Keys dietary lipid score, predictive of serum total cholesterol, was calculated as $1.35 \times$ (2SFA -PUFA) $+1.5 \times \mathrm{C}^{1 / 2}$, where SFA is the percentage of total kilocalories from saturated fatty acids; PUFA, percentage from polyunsaturated fatty acids; $\mathrm{C}$ dietary cholesterol in $\mathrm{mg} / 1000 \mathrm{kcal}$ [13]. BMI was calculated as weight divided by height squared $\left(\mathrm{kg} / \mathrm{m}^{2}\right)$. Sample average number of cigarettes smoked per day was calculated for current smokers only and for all persons including non-smokers. Student's t-tests were used to compare means of Japanese and Japanese-Americans; chi-squared tests, to compare smoking rates, use of lipid lowering and anti-hypertensive drugs.

Based on significant Hawaii-Japan univariate differences for non-dietary and dietary variables in both men and women, gender-specific multiple linear regression models were used to examine the relations of dietary factors and physical activity to Hawaii-Japan differences in leptin concentration, with control for non-dietary variables [14]. Because the distribution of serum leptin was positively skewed, a logarithmic transformation was used to normalize the distribution (log-leptin). The basic model (Model 1) included age and an indicator for site (Hawaii=1, Japan=0) to obtain the gender-specific age-adjusted coefficient for Hawaii-Japan differences in log-leptin. Addition of number of cigarettes smoked per day or physical activity, BMI, or postprandial hour to Model 1 was also examined. Model 2 included physical activity in addition to Model 1 variables. Model 3 included BMI and number of cigarettes smoked per day in addition to Model 2 variables. Then, each dietary factor possibly explaining remaining Hawaii-Japan differences in leptin concentration was added to Model 2 and 3 separately, and percentage total and further reduction in the site coefficient was calculated to assess influence of the added variable on Hawaii-Japan logleptin differences. Finally, dietary variables were included in combinations to assess their joint impact on Hawaii-Japan differences in log-leptin.

\section{Results}

\section{Demographic Characteristics and Blood Chemistry Concentrations}

For both men and women, mean leptin concentration was significantly higher in Hawaii than in Japan (Table 1). For both participants in Hawaii and Japan, mean leptin concentration was significantly higher in women than in men (both $\mathrm{P}<0.0001$ by Student's t-test on log-leptin). Mean BMI was significantly higher in men than in women in Hawaii $(\mathrm{P}=0.0001)$, however, it was not different between men and women in Japan $(\mathrm{P}=0.97)$. Average height was similar for Japanese in Japan and Japanese in Hawaii. Average BMI was significantly higher in Hawaii than in Japan $(\mathrm{P}<0.0001$ and 0.0001$)$ for both men and women with the difference greater for men than women. Prevalence of premenopause was not different between women in Japan and Hawaii $(\mathrm{P}=0.23)$. Smoking rate in men and mean for moderate + heavy 
physical activity (hours/day) in men and women were lower in Hawaii than in Japan ( $\mathrm{P}<$ 0.0001). Antihypertensive and lipid lowering drugs were used by a significantly greater percentage of individuals of both genders in Hawaii than in Japan. Mean postprandial hour was not different between men in Japan and Hawaii, however it was significantly shorter in women in Japan than in Hawaii $(\mathrm{P}=0.04)$. Mean LDL-C, HbA1c in men and women were higher in Hawaii than in Japan.

\section{Nutrient Intakes}

Most displayed nutrient intakes were significantly different across the two samples (Table 2). Mean intakes (\% kcal) of total fat, SFA, MUFA, PUFA, n-6 PUFA, and ARA in men and women were higher in Hawaii than in Japan. Participants in Hawaii consumed lower percentages of total calories from carbohydrates, n-3 PUFA, EPA, DHA, DPA (also less cholesterol) than in Japan $(\mathrm{P}<0.0001)$. Mean Keys dietary lipid score in men was significantly higher in Hawaii than in Japan $(\mathrm{P}<0.0001)$. Men in Hawaii ingested lower percentage of total calories from alcohol than men in Japan $(\mathrm{P}<0.0001)$.

\section{Relation of Dietary Variables to Leptin and Hawaii-Japan Leptin Differences}

Table 3 gives coefficients from multiple linear regression models used to examine relations of factors to Hawaii-Japan difference in log-leptin concentration in men and women. In men, addition to Model 1 of BMI reduced this leptin difference by $92.4 \%$. The P-value for the Honolulu-Aito Town difference in serum leptin decreased from $<0.0001$ to 0.51 . Addition of physical activity to Model 1 (Model 2) reduced Hawaii-Japan difference in log-leptin only slightly (13.3\%); the P-value remained significant $(<0.0001)$. Because BMI had strong impact on Hawaii-Japan difference in log-leptin, inclusion of BMI in models may washout potential effects of nutrient factors on leptin. Thus, additions of nutrient factors to Model 2 (without BMI) were examined one by one. The results of nutrient factors with significant relationship with log-leptin in men or women are shown. In men, only dietary fiber had significant relationship with log-leptin (coefficient $b=-0.020, \mathrm{P}=0.007$ ). Addition of BMI and number of cigarettes smoked per day to Model 2 (Model 3) reduced Hawaii-Japan difference in log-leptin remarkably $(99.99 \%, \mathrm{P}=0.99)$. Thus in men, the sizable difference in BMI across the two populations statistically accounted for most of the serum leptin difference.

In women, addition to Model 1 of BMI reduced the coefficient for Hawaii-Japan leptin difference by $46.6 \%$. Addition of postprandial hour to Model 1 did not change the coefficient for Hawaii-Japan leptin difference. Addition of physical activity to Model 1 (Model 2) reduced Hawaii-Japan difference in log-leptin only slightly $(0.1 \%)$; the P-value remained significant $(<0.0001)$. By addition of dietary factors to Model 2 , dietary factors found to have significant relationship with log-leptin were arachidonic acid $(b=1.3$, $\mathrm{P}=0.004)$, Keys dietary lipid score $(\mathrm{b}=0.0045, \mathrm{P}=0.03)$, alcohol intake $(\mathrm{b}=-0.021, \mathrm{P}=0.03)$, and dietary fiber $(\mathrm{b}=-0.012, \mathrm{P}=0.04)$. With addition of $\mathrm{BMI}$ and number of cigarettes smoked per day to Model 2, percent reduction in the coefficient increased slightly to $49.0 \%$ (Model 3). Except for alcohol, addition to Model 3 of nutrients shown in Table 2, singly, had no significant independent relation to leptin, and these dietary variables singly did not reduce the coefficient for log-leptin difference significantly. With addition to Model 3 of alcohol (\%kcal), overall percent reduction in the coefficient was $49.1 \%$; alcohol had a significant independent inverse relation to log-transformed serum leptin $(\mathrm{P}=0.023)$. The $\mathrm{P}$ value for the Honolulu-Aito Town difference in log-leptin decreased slightly from <0.0001 to 0.0006 . With addition to Model 3 of alcohol, total dietary fiber and iron (mg/1000kcal), percent reduction in the coefficient increased to $70.7 \%$. The P-value for the Honolulu-Aito Town difference in log-transformed serum leptin decreased from $<0.0001$ to 0.126 , although none of these variables except for alcohol, had a significant independent relation to leptin. 


\section{Discussion}

Main findings here were: serum leptin concentrations were significantly higher in population samples of Japanese-Americans in Hawaii than Japanese in Japan, people of the same genetic background. In men, adjustment for higher BMI in Hawaiian Japanese-Americans reduced the log-leptin Hawaii -Japan difference by $92 \%$, to a nonsignificant level. In women, BMI reduced this difference by only $47 \%$; further adjustment for three dietary factors (iron, fiber, alcohol) produced further reduction in the difference, to $71 \%$.

There have been several studies on the association between dietary intakes and leptin concentrations. Raben et al. examined the acute effect of four isocaloric meals rich in alcohol, protein, carbohydrate or fat on serum leptin concentrations; they found leptin concentrations greatly suppressed the first 4 hours after the alcohol meal [15]. A very slight suppression of leptin concentration was seen the first 3 hours after the other meals. Postprandial stability of leptin also has been shown in normal and obese persons, as well as in patients with type II diabetes mellitus [12]. Therefore, slight difference in postprandial hour between women in Japan and Hawaii found in our study might not have contributed the site difference in leptin concentrations. In fact, addition of postprandial hour to Model 1 did not change the coefficient for Hawaii-Japan leptin difference in our study.

There have been discrepancies as to the long-term effect of alcohol on leptin; some reported an increase, others a decrease or no change [16-18]. A cross-sectional study by Yannakoula et al. in 120 healthy Greek male and female students found that protein, carbohydrate, and fat intakes were not correlated with leptin concentrations in multiple regression analyses [19]. Another cross-sectional study by Murakami et al. in 424 female students reported that only dietary fiber was inversely correlated with leptin concentrations independent of potential confounding factors, including BMI; protein, total fat, SFA, MUFA, PUFA, and carbohydrate were not correlated with leptin concentration [20]. A study by Chu et al. among 268 normal weight and overweight men, on the other hand, found that total fat and MUFA intakes were positively associated with leptin concentrations independent of BMI and other confounding factors only in men with BMI $<25.0 \mathrm{~kg} / \mathrm{m}^{2}[21]$.

Dietary fiber was the only nutrient that had consistently significant inverse relationship with leptin in both men and women in our study. Our results agree with those of Murakami et al. [20] High intake of dietary fiber has been linked to a lower risk of coronary heart disease and type 2 diabetes mellitus in several epidemiological studies [22-24]. Because dietary fiber is indigestible and not absorbed in the intestine, the benefit from intake of dietary fiber is thought that the viscosity of dietary components may modify the rate and the site of nutrient absorption, fermentation of polysaccharides in the large intestine may produce products that affect metabolism, and binding of compounds, such as bile acids, affects the excretion of the compounds [25]. Another possible mechanism may be a change in dietary pattern, resulting in a diet that is lower in saturated and trans-unsaturated fats and cholesterol and higher in protective nutrients such as an unsaturated fatty acids, minerals, folate, and antioxidant vitamins. It is understandable that these beneficial effects resulted in inverse relationship of dietary fiber with leptin. However, these relationships were not independent of BMI in our study.

Our results in women support the conclusion that alcohol intake suppresses leptin concentration by Raben et al. [15]. The relationship in our study, however, was not independent of BMI. We found direct association of arachidonic acid with leptin in women. No previous epidemiological study examined this relationship, Fain et al. found that arachidonic acid stimulated leptin release by explants of subcutaneous adipose tissue from obese humans [26]. This relation in our study also was not independent of BMI. BMI 
dependent direct association of Keys dietary lipid score with leptin in our study in women is not found in previous studies, however, it is understandable.

As to other lifestyle factors possibly related to leptin concentration, several studies have examined the response of leptin to exercise. It appears that nonexhausive exercise of short duration does not affect leptin, whereas bouts demanding high-energy decrease leptin concentration [27-29]. Sedentary lifestyles, as represented by average hours of television watching per week, have been found by Fung et al. to associate directly with leptin concentration [30]. Smoking was reported in some studies to reduce leptin concentration [31,32], however, one study found little relationship between smoking and leptin in Greek men [33]. In our regression models without BMI, in men, but not in women, there were modest inverse associations of smoking and physical exercise with leptin concentration.

Collectively, dietary factors that had significant association with leptin in our study were dietary fiber in both sexes, and alcohol in women; these were BMI dependent associations. Three major nutrient factors did not have significant associations with leptin. These results mostly agree with those of previous studies. However, BMI independent association of dietary fiber with leptin in the study by Murakami et al. [20] was not confirmed in our study. Very wide range of BMI in our participants, whereas a relatively narrow range of BMI in the study by Murakami et al. might have caused the slight difference.

Japanese living in Japan had higher intake of dietary cholesterol than those in Hawaii. Although, we have not food group data yet, previous studies reported that egg consumption contributed to 26 to $32 \%$ to total dietary cholesterol intake in the U.S. [34,35], whereas that in Japan was reported to contribute to about $48 \%$ in Japan [36]. Mean LDL concentration was higher in men and women in Hawaii than those in Japan despite a lower intake of dietary cholesterol was due mostly to a higher intake of SFA in persons in Hawaii than those in Japan.

The main strengths of the present study are: (1) use of population-based samples; (2) standardized collection of high-quality BP and nutrition data; (3) use of an improved nutrient database; and (4) use of multiple quality-control procedures. The study was limited by its two-sample cross-sectional design, and small number of participants. Findings may or may not be generalizable to all Japanese and to other populations. Second, despite highquality dietary nutrient data acquisition methods, limitation in reliability may still bias against nutritional variables influence in multivariate models. Third, we did not measure waist circumference (WC). However, we showed previously in a population-based study that BMI and WC correlated very well in men and women, and that BMI could be used instead of WC in a study when the latter was not available [37]. Although the measurement of WC is widely advocated as a simple anthropometric marker of health risk, there remains no uniformly accepted protocol [38,39]. Forth, we did not measure subcutaneous adipose tissue area and visceral adipose tissue area by computer tomography. There were more dietary factors in women than in men that were significantly associated with leptin. In addition, BMI contributed more strongly in men than in women for explanation of the logleptin Hawaii-Japan difference. These sex specific difference in the association of BMI and dietary factors with leptin found in the present study may be related to sex related difference in fat mass distribution. Data on subcutaneous adipose tissue area and visceral adipose tissue area might have helped the interpretation.

In conclusion, Mean leptin concentration was significantly higher in Hawaii than in Japan for both genders. In men, this difference related overwhelmingly to BMI; in women, to BMI and physical activity, with three specific dietary factors (iron, fiber, alcohol) playing a modest role in further reduction of the leptin difference. 


\section{Acknowledgments}

This study was supported in part by the grant-in-aid of the Japanese Ministry of Education, Culture, Sports, Science and Technology (Grant-in-Aid for Scientific Research: (A) 090357003, (C)17590563 and (C)19590655 in Japan and the Suntory Company; the Pacific Research Institute is supported by the Robert Perry Fund and the Hawaii Community Foundation. The INTERMAP Hawaii Center was funded by the National Heart, Lung, and Blood Institute, National Institutes of Health (Grant 5-RO1-HL54868-03). The INTERMAP Study is supported by the National Heart, Lung, and Blood Institute, National Institutes of Health, Bethesda, MD, U.S.A. (Grant 2-RO1HL50490-06), as well as national and local agencies in the four countries.

The INTERMAP Study has been accomplished through the fine work of the staff at local, national, and international centers. A partial listing of colleagues is in the acknowledgement of reference 8 .

\section{References}

1. Zhang Y, Proenca R, Maffei M, Barone M, Leopold L, Friedman JM. Positional cloning of the mouse obese gene and its human homologue. Nature. 1994; 372:425-32. [PubMed: 7984236]

2. Haynes WG, Morgan DA, Walsh SA, Mark AL, Sivitz WI. Receptor-mediated regional sympathetic nerve activation by leptin. J Clin Invest. 1997; 100:270-8. [PubMed: 9218503]

3. Heymsfield SB, Greenberg AS, Fujioka K, Dixon RM, Kushner R, Hunt T, et al. Recombinant leptin for weight loss in obese and lean adults: a randomized, controlled, dose-escalation trial. JAMA. 1999; 282:1568-75. [PubMed: 10546697]

4. Correia ML, Rahmouni K. Role of leptin in the cardiovascular and endocrine complications of metabolic syndrome. Diabetes Obes Metab. 2006; 8:603-10. [PubMed: 17026484]

5. Correia ML, Haynes WG, Rahmouni K, Morgan DA, Sivitz WI, Mark AL. The concept of selective leptin resistance: evidence from agouti yellow obese mice. Diabetes. 2002; 51:439-42. [PubMed: 11812752]

6. Ueshima H, Okayama A, Saitoh S, Nakagawa H, Rodriguez B, Sakata K, et al. Differences in cardiovascular disease risk factors between Japanese in Japan and Japanese-Americans in Hawaii: the INTERLIPID study. J Hum Hypertens. 2003; 17:631-9. [PubMed: 13679953]

7. Okuda N, Ueshima H, Okayama A, Saitoh S, Nakagawa H, Rodriguez BL, et al. Relation of long chain n-3 polyunsaturated fatty acid intake to serum high density lipoprotein cholesterol among Japanese men in Japan and Japanese-American men in Hawaii: the INTERLIPID study. Atherosclerosis. 2005; 178:371-9. [PubMed: 15694947]

8. Stamler J, Elliott P, Dennis B, Dyer AR, Kesteloot H, Liu K, et al. INTERMAP: background, aims, design, methods, and descriptive statistics (nondietary). J Hum Hypertens. 2003; 17:591-608. [PubMed: 13679950]

9. Nakamura M, Morita M, Yabuuchi E, Yukami M, Kuruma S, Kuritani C, et al. The evaluation of cooperative cholesterol and triglyceride standardization program by WHO-CDC (in Japanese). Rinsho Byori. 1982; 30:325-32. [PubMed: 6287057]

10. Myers GL, Kimberly MM, Waymack PP, Smith SJ, Cooper GR, Sampson EJ. A reference method laboratory network for cholesterol: a model for standardization and improvement of clinical laboratory measurements. Clin Chem. 2000; 46:1762-72. [PubMed: 11067811]

11. Craig SR, Amin RV, Russell DW, Paradise NF. Blood cholesterol screening influence of fasting state on cholesterol results and management decisions. J Gen Intern Med. 2000; 15:395-9. [PubMed: 10886474]

12. Korbonits M, Trainer PJ, Little JA, Edwards R, Kopelman PG, Besser GM, et al. Leptin levels do not change acutely with food administration in normal or obese subjects, but are negatively correlated with pituitary-adrenal activity. Clin Endocrinol (Oxf). 1997; 46:751-7. [PubMed: 9274707]

13. Keys A. Serum cholesterol response to dietary cholesterol. Am J Clin Nutr. 1984; 40:351-9. [PubMed: 6465065]

14. Elliott P, Stamler J, Dyer AR, Appel L, Dennis B, Kesteloot H, et al. Association between protein intake and blood pressure: the INTERMAP Study. Arch Intern Med. 2006; 166:79-87. [PubMed: 16401814] 
15. Raben A, Agerholm-Larsen L, Flint A, Holst JJ, Astrup A. Meals with similar energy densities but rich in protein, fat, carbohydrate, or alcohol have different effects on energy expenditure and substrate metabolism but not on appetite and energy intake. Am J Clin Nutr. 2003; 77:91-100. [PubMed: 12499328]

16. Nicolás JM, Fernández-Solà J, Fatjó F, Casamitjana R, Bataller R, Sacanella E, et al. Increased circulating leptin levels in chronic alcoholism. Alcohol Clin Exp Res. 2001; 25:83-8. [PubMed: 11198718]

17. Roth MJ, Baer DJ, Albert PS, Castonguay TW, Dorgan JF, Dawsey SM, et al. Relationship between serum leptin levels and alcohol consumption in a controlled feeding and alcohol ingestion study. J Natl Cancer Inst. 2003; 95:1722-5. [PubMed: 14625264]

18. Calissendorff J, Brismar K, Röjdmark S. Is decreased leptin secretion after alcohol ingestion catecholamine-mediated? Alcohol Alcohol. 2004; 39:281-6. [PubMed: 15208157]

19. Yannakoulia M, Yiannakouris N, Blüher S, Matalas AL, Klimis-Zacas D, Mantzoros CS. Body fat mass and macronutrient intake in relation to circulating soluble leptin receptor, free leptin index, adiponectin, and resistin concentrations in healthy humans. J Clin Endocrinol Metab. 2003; 88:1730-6. [PubMed: 12679465]

20. Murakami K, Sasaki S, Takahashi Y, Uenishi K, Yamasaki M, Hayabuchi H, et al. Nutrient and food intake in relation to serum leptin concentration among young Japanese women. Nutrition. 2007; 23:461-8. [PubMed: 17573997]

21. Chu NF, Stampfer MJ, Spiegelman D, Rifai N, Hotamisligil GS, Rimm EB. Dietary and lifestyle factors in relation to plasma leptin concentrations among normal weight and overweight men. Int $\mathrm{J}$ Obes Relat Metab Disord. 2001; 25:106-14. [PubMed: 11244465]

22. Pereira MA, O'Reilly E, Augustsson K, et al. Dietary fiber and risk of coronary heart disease: a pooled analysis of cohort studies. Arch Intern Med. 2004; 164:370-6. [PubMed: 14980987]

23. Rimm EB, Ascherio A, Giovannucci E, Spiegelman D, Stampfer MJ, Willett WC. Vegetable, fruit, and cereal fiber intake and risk of coronary heart disease among men. JAMA. 1996; 275:447-51. [PubMed: 8627965]

24. Krishnan S, Rosenberg L, Singer M, et al. Glycemic index, glycemic load, and cereal fiber intake and risk of type 2 diabetes in US black women. Arch Intern Med. 2007; 167:2304-9. [PubMed: 18039988]

25. Schneeman BO. Dietary fiber and gastrointestinal function. Nutr Res. 1998; 18:625-32.

26. Fain JN, Leffler CW, Cowan GS Jr, Buffington C, Pouncey L, Bahouth SW. Stimulation of leptin release by arachidonic acid and prostaglandin $\mathrm{E}(2)$ in adipose tissue from obese humans. Metabolism. 2001; 50:921-8. [PubMed: 11474480]

27. Desgorces FD, Chennaoui M, Gomez-Merino D, Drogou C, Guezennec CY. Leptin response to acute prolonged exercise after training in rowers. Eur J Appl Physiol. 2004; 91:677-81. [PubMed: 14704800]

28. Kraemer RR, Chu H, Castracane VD. Leptin and exercise. Exp Biol Med (Maywood). 2002; 227:701-8. [PubMed: 12324651]

29. Olive JL, Miller GD. Differential effects of maximal- and moderate-intensity runs on plasma leptin in healthy trained subjects. Nutrition. 2001; 17:365-9. [PubMed: 11377127]

30. Fung TT, Hu FB, Yu J, Chu NF, Spiegelman D, Tofler GH, et al. Leisure-time physical activity, television watching, and plasma biomarkers of obesity and cardiovascular disease risk. Am J Epidemiol. 2000; 152:1171-8. [PubMed: 11130623]

31. Reseland JE, Mundal HH, Hollung K, Haugen F, Zahid N, Anderssen SA, et al. Cigarette smoking may reduce plasma leptin concentration via catecholamines. Prostaglandins Leukot Essent Fatty Acids. 2005; 73:43-9. [PubMed: 15964536]

32. Sugiura K, Tamakoshi K, Yatsuya H, Otsuka R, Wada K, Matsushita K, et al. Low leptin but high insulin resistance of smokers in Japanese men. Diabetes Res Clin Pract. 2008; 81:358-64. [PubMed: 18579252]

33. Lagiou P, Signorello LB, Mantzoros CS, Trichopoulos D, Hsieh CC, Trichopoulou A. Hormonal, lifestyle, and dietary factors in relation to leptin among elderly men. Ann Nutr Metab. 1999; 43:23-9. [PubMed: 10364627] 
34. Dawber TR, Nickerson RJ, Brand FN, Pool J. Eggs, serum cholesterol, and coronary heart disease. Am J Clin Nutr. 1982; 36:617-25. [PubMed: 7124663]

35. Hu FB, Stampfer MJ, Rimm EB, Manson JE, Ascherio A, Colditz GA, et al. A prospective study of egg consumption and risk of cardiovascular disease in men and women. JAMA. 1999; 281:1387-94. [PubMed: 10217054]

36. Yoshida Y, Okayama A, Makita K, Ueshima H, Kita Y, Fujita Y, et al. Dietary intake and its relationship to serum cholesterol concentrations among three Japanese populations in the early 1990s: INTERSALT II study in Japan. Journal of Shiga University of Medical Science. 1998; 13:63-79.

37. Nakamura Y, Turin TC, Kita Y, Tamaki S, Tsujita Y, Kadowaki T, et al. The associations of obesity measures with the metabolic risk factors in a community-based opulation in Japan. Circ J. 2007; 71:776-781. [PubMed: 17457008]

38. Mason C, Katzmarzyk PT. Variability in waist circumference measurements according to anatomic measurement site. Obesity. 2009; 17:1789-1795. [PubMed: 19343017]

39. Panoulas VF, Ahmad N, Fazal AA, Kassamali RH, Nightingale P, Kitas GD, et al. The interoperator variability in measuring waist circumference and its potential impact on the diagnosis of the metabolic syndrome. Postgrad Med J. 


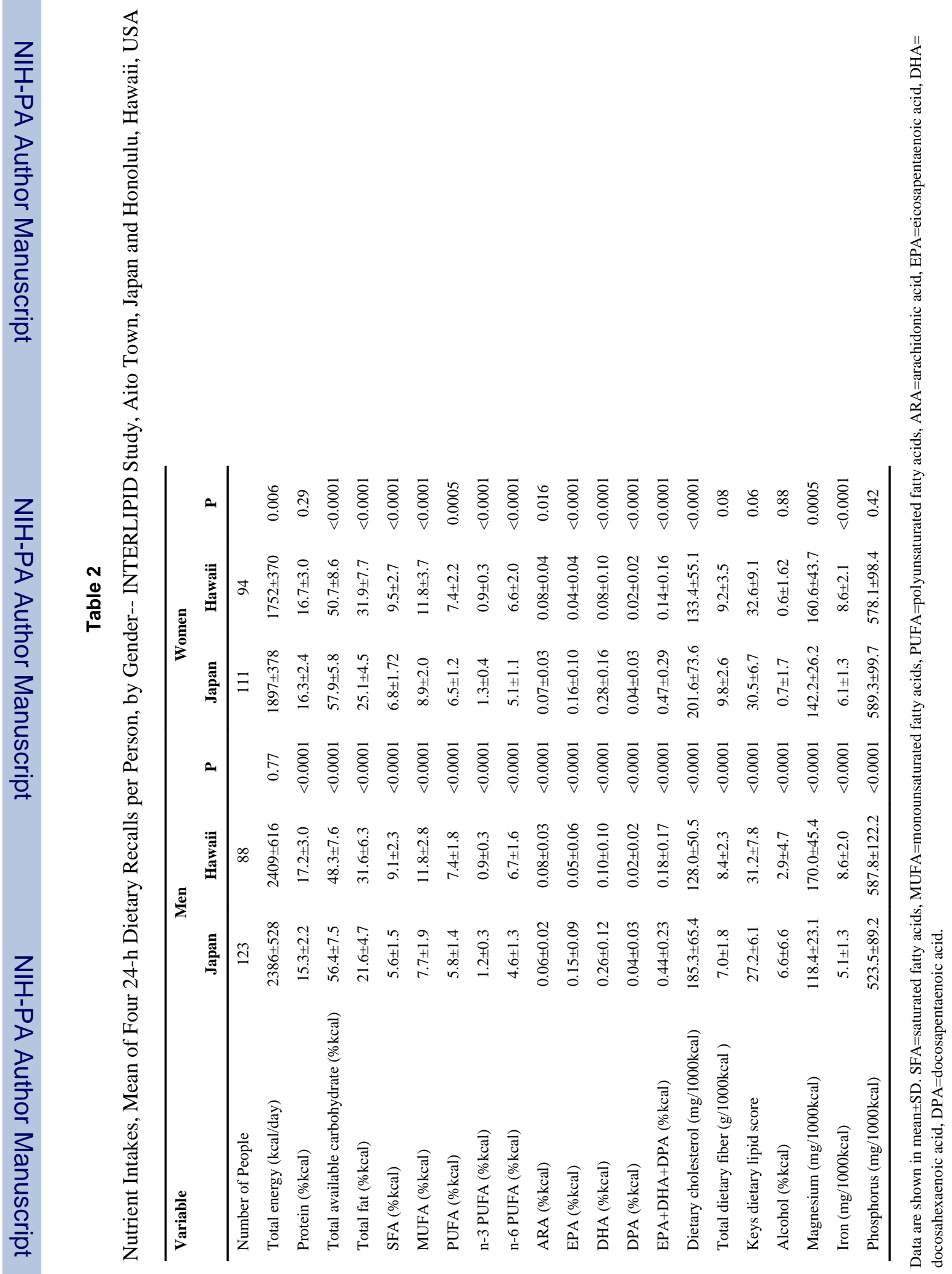


Table 3

Relation of Variables to Hawaii-Japan Log-transformed Serum Leptin Difference byGender--INTERLIPID Study, Aito Town, Japan and Honolulu, Hawaii in USA.

\begin{tabular}{|c|c|c|c|c|}
\hline Model & $\begin{array}{c}\text { Coefficient } \\
\text { for Site } \\
\text { (Japan=0) }\end{array}$ & $P$ value for Site & $\begin{array}{l}\text { Coefficient for } \\
\text { Other Variable }\end{array}$ & $\begin{array}{c}\% \text { change in Site } \\
\text { Coeff. from Model } \\
1\end{array}$ \\
\hline \multicolumn{5}{|l|}{ Men } \\
\hline Model 1 (Site, Age) & 0.245 & $<0.0001$ & & \\
\hline Model 1+Cigarettes/d & 0.210 & $<0.0001$ & $-0.0033^{*}$ (cigarettes) & 14.4 \\
\hline Model 1 +BMI & 0.0186 & 0.51 & $0.045^{* *}(\mathrm{BMI})$ & 92.4 \\
\hline Model 2 (Model 1+Physical) & 0.212 & $<0.0001$ & $-0.013^{* *}($ physical $)$ & 13.3 \\
\hline Model 2+ ARA & 0.216 & $<0.0001$ & -0.235 & 11.8 \\
\hline Model 2+Keys dietary lipid score & 0.204 & $<0.0001$ & 0.00228 & 16.7 \\
\hline Model 2+ Alcohol & 0.214 & $<0.0001$ & 0.000348 & 12.7 \\
\hline Model 2+Fiber & 0.240 & $<0.0001$ & $-0.0204^{* *}$ & 2.0 \\
\hline Model 2+Iron & 0.237 & $<0.0001$ & -0.00762 & 3.3 \\
\hline Model 3 (Model 2+BMI, Cigarettes/d) & 0.0002 & 0.99 & & 99.99 \\
\hline \multicolumn{5}{|l|}{ Women } \\
\hline Model 1 (Site, Age) & 0.188 & $<0.0001$ & & \\
\hline Model 1+Cigarettes/d & 0.187 & $<0.0001$ & -0.0012 (cigarettes) & 0.4 \\
\hline Model $1+$ BMI & 0.100 & $<0.0001$ & $0.037^{* *}(\mathrm{BMI})$ & 46.6 \\
\hline Model $1+$ postprandial hr & 0.188 & $<0.0001$ & -0.0002 (postprandial hr) & 0 \\
\hline Model 2 (Model 1+Physical) & 0.188 & $<0.0001$ & -0.00006 (physical) & 0.1 \\
\hline Model 2+ ARA & 0.171 & $<0.0001$ & $1.3^{* *}$ & 9.0 \\
\hline Model 2+Keys dietary lipid score & 0.179 & $<0.0001$ & $0.0045^{*}$ & 4.8 \\
\hline Model 2+ Alcohol & 0.186 & $<0.0001$ & $-0.021^{*}$ & 1.1 \\
\hline Model 2+Fiber & 0.176 & $<0.0001$ & $-0.012^{*}$ & 6.4 \\
\hline Model 2+Iron & 0.188 & $<0.0001$ & -0.00032 & 0 \\
\hline Model 3 (Model 2 +BMI, Cigarettes/d) & 0.0958 & 0.0006 & & 49.0 \\
\hline Model 3+Protein & 0.0952 & 0.0006 & 0.003 & 49.3 \\
\hline Model 3+Carbohydrates & 0.103 & 0.0005 & 0.001 & 45.3 \\
\hline Model 3+Total fat & 0.102 & 0.0008 & -0.001 & 45.9 \\
\hline Model 3+Total n-3 PUFA & 0.103 & 0.0011 & 0.017 & 45.2 \\
\hline Model 3+EP_DH_DP & 0.101 & 0.002 & 0.015 & 46.4 \\
\hline Model 3+ARA & 0.0938 & 0.0008 & 0.259 & 50.1 \\
\hline Model 3+Fiber & 0.0931 & 0.0009 & -0.004 & 50.5 \\
\hline Model 3+Magnesium & 0.0951 & 0.0007 & 0.00003 & 48.4 \\
\hline Model 3+Iron & 0.0863 & 0.0082 & 0.004 & 54.1 \\
\hline Model 3+Phosphorous & 0.0972 & 0.0006 & 0.00001 & 48.5 \\
\hline Model 3+Alcohol & 0.0957 & 0.0005 & $-0.016^{*}$ & 49.1 \\
\hline Model 3+Alcohol, Fiber & 0.0927 & 0.0008 & $\begin{array}{c}-0.016 * \text { (alcohol) } \\
-0.004 \text { (fiber) }\end{array}$ & 50.7 \\
\hline
\end{tabular}




\begin{tabular}{|c|c|c|c|c|}
\hline Model & $\begin{array}{l}\text { Coefficient } \\
\text { for Site } \\
\text { (Japan=0) }\end{array}$ & $P$ value for Site & $\begin{array}{l}\text { Coefficient for } \\
\text { Other Variable }\end{array}$ & $\begin{array}{c}\% \text { change in Site } \\
\text { Coeff. from Model } \\
1\end{array}$ \\
\hline Model 3+Alcohol, Fiber, Phosphorus & 0.0936 & 0.0007 & $\begin{array}{c}-0.016 * \text { (alcohol) } \\
-0.004 \text { (fiber) } \\
0.0001 \text { (phos) }\end{array}$ & 50.2 \\
\hline Model 3+Alcohol, Fiber, Magnesium & 0.0750 & 0.016 & $\begin{array}{c}-0.017^{*} \text { (alcohol), } \\
-0.010 \text { (fiber) } \\
0.0007 \text { (magn) }\end{array}$ & 60.1 \\
\hline Model 3+Alcohol, Fiber, Iron & 0.0551 & 0.126 & $\begin{array}{c}-0.017^{*} \text { (alcohol), } \\
-0.009 \text { (fiber) } \\
0.014 \text { (iron) }\end{array}$ & 70.7 \\
\hline
\end{tabular}

Coefficients for multiple linear regression models used to examine the relations of lifestyle factors to Hawaii-Japan differences in log-transformed leptin concentration in men (123 in Japan and 88 in Hawaii) and women (111 in Japan and 94 in Hawaii), with control for non-dietary variables as shown.. P values for site coefficient are presented. P values for the other coefficients are indicated by

* $\mathrm{P}<0.05$,

** $\mathrm{P}<0.01$.

BMI=body mass index, Physical Activity=moderate or heavy physical activity, usual number of hours per day, SFA=saturated fatty acids, MUFA=monounsaturated fatty acids, $\mathrm{PUFA}=$ polyunsaturated fatty acids, $\mathrm{EPA}=$ eicosapentaenoic acid, DHA= docosahexaenoic acid,

DPA=docosapentaenoic acid, ARA=arachidonic acid, EP_DH_DP=EPA+DHA+DPA 